\title{
PREPARATION OF ALUMINIUM OXIDE NANOPARTICLES USING GREEN SYNTHESIS
}

\author{
${ }^{1}$ Sivaranjani RAVICHANDRAN, ${ }^{1}$ Ramya Devi DURAI, ${ }^{1}$ Priya Dharshini KRISHNAN, \\ ${ }^{2} \mathrm{P}$. RAMESHKUMAR, ${ }^{3}$ Tiju THOMAS, ${ }^{4}$ Sathiya N. NARAYANAN, ${ }^{5,6}$ Bozena HOSNEDLOVA, \\ ${ }^{7}$ Barbora HAVELKOVA, ${ }^{5,8}$ Milan JAKUBEK, ${ }^{7}$ Miroslava BEKLOVA,,${ }^{5,67,9}$ Rene KIZEK, \\ ${ }^{1}$ Vedha Hari B NARAYANAN* \\ ${ }^{1}$ Pharmaceutical Technology Lab, School of Chemical \& Biotechnology, SASTRA Deemed University, \\ Thanjavur, India, vedhahari@scbt.sastra.edu \\ ${ }^{2}$ Mandapam Regional Centre of Central Marine Fisheries Research Institute, Marine Fisheries P. O. \\ Mandapam Camp, Tamil Nadu, India \\ ${ }^{3}$ Applied Nanostructures Engineering and Nanochemistry, ANEN, Department of Metallurgical and Materials \\ Engineering, Indian Institute of Technology Madras, Chennai, India \\ ${ }^{4}$ School of Mechanical Engineering, SASTRA Deemed University, Thanjavur, India \\ ${ }^{5}$ BIOCEV, First Faculty of Medicine, Charles University, Vestec, Czech Republic, EU, \\ bozena.hosnedlova@post.cz, Milan.Jakubek@lf1.cuni.cz \\ ${ }^{6}$ CONEM Metallomics Nanomedicine Research Group (CMNRG), Vinohrady, Prague, Czech Republic, EU, \\ kizek@sci.muni.cz \\ ${ }^{7}$ Department of Ecology and Diseases of Zooanimals, Game, Fish and Bees, Faculty of Veterinary Hygiene \\ and Ecology, University of Veterinary Brno, Czechia, EU, havelkovab@vfu.cz, beklovam@vfu.cz \\ ${ }^{8}$ Department of Pediatrics and Inherited Metabolic Disorders, First Faculty of Medicine, Charles University, \\ Prague, Czech Republic, EU \\ ${ }^{9}$ Department of Biomedical and Environmental Analyses, Faculty of Pharmacy, Wroclaw Medical University, \\ Wroclaw, Poland, EU \\ *Correspondence: kizek@sci.muni.cz; vedhahari@scbt.sastra.edu; Tel./Fax: +42-05-4156-2820
}

https://doi.org/10.37904/nanocon.2021.4362

\begin{abstract}
Nanoparticles are widely used in industry as well as biomedicine. An interesting group are aluminium oxide nanaoparticles (alumina nanoparticles) belonging to the family of metal oxide nanoparticles, which can be prepared by various methods (the sol-gel, precipitation, micro-emulsion and hydrothermal methods). In this work, alumina nanoparticles were prepared by biological synthesis using plant extract from fresh neem (Azadirachta indica) leaves. The particles were confirmed by the SEM analysis. The distribution diagram showed a size from 60 to 1,500, with a maximum around 200-400 nm. Alumina nanoparticles possess many potential applications in biomedicine such as drug delivery, therapy of cancer and other diseases, and immunotherapy.
\end{abstract}

Keywords: Aluminium nanoparticles, green synthesis; biotechnology; nanomedicine

\section{INTRODUCTION}

The sol-gel technique is one of the optimistic and explored methods due to its ability to produce ultrafine sized particles with controlled size, high surface area, purity, and crystallinity. Figure 1 shows a schematic representation of the synthesis of alumina nanoparticles by using an ethanol solution of iron nitrate as precursor through the simple sol-gel method [1]. 
Rogojan et al. prepared aluminium oxide nanopowders using 2 different precursors, organic and inorganic precursors to be used as a biomaterial in medical applications. The organic precursor used was aluminium chloride $\left(\mathrm{AlCl}_{3}\right)$ and the inorganic precursor was aluminium triisopropylate $\mathrm{Al}\left[\mathrm{OCH}\left(\mathrm{CH}_{3}\right)_{2}\right]_{3}$. [2]. The precursors were chemically treated by using the sol-gel protocol, and the resulting gel was calcined for 2 hours at two different temperatures, $1,000^{\circ} \mathrm{C}$ and $1,200^{\circ} \mathrm{C}$. The $\mathrm{X}$-ray diffraction analysis revealed that thermal treatment at $1,000{ }^{\circ} \mathrm{C}$ leads to the formation of $\alpha+\gamma-\mathrm{Al}_{2} \mathrm{O}_{3}$ mixture having relatively low degrees of crystallinity. An increase in the heat treatment temperature to $1200^{\circ} \mathrm{C}$ led to the formation of $\alpha-\mathrm{Al}_{2} \mathrm{O}_{3}$ with higher crystallinity. The SEM and TEM analysis confirmed the production of alumina powder in nanometer-scale by the sol-gel method. Application of heat treatment at temperatures higher than $1,000{ }^{\circ} \mathrm{C}$ had led to the formation of crystalline $\alpha$ alumina as a single phase.

$\mathrm{Li}$ et al. synthesized nano-sized $\mathrm{\alpha}-\mathrm{Al}_{2} \mathrm{O}_{3}$ powder using citrate precursor that was derived from aluminium nitrate and citric acid precursor solution. The ratio of citric acid $(\mathrm{CA})$ to metal nitrate $(\mathrm{N})$ had a greater influence on the size of the nanoparticle prepared by the sol-gel method. Initially, the ratio was maintained as $1: 1$ and the precursors were heated to $400{ }^{\circ} \mathrm{C}$. The precursors decomposed and resulted in the formation of amorphous nano- $\mathrm{Al}_{2} \mathrm{O}_{3}$, which further transformed into to $\mathrm{y}-\mathrm{Al}_{2} \mathrm{O}_{3}$ (size $=15 \mathrm{~nm}$ ). Further heating to $800^{\circ} \mathrm{C}$ resulted in the transformation of $\mathrm{Y}-\mathrm{Al}_{2} \mathrm{O}_{3}$ to $\alpha-\mathrm{Al}_{2} \mathrm{O}_{3}$ with a crystalline size of $75 \mathrm{~nm}$. The calcination process was completed at $1,000{ }^{\circ} \mathrm{C}$ with the formation of $200 \mathrm{~nm}$-sized alumina nanoparticles. The increasing molar ratio of $\mathrm{CA} / \mathrm{N}$ favored the rapid phase transition of $\mathrm{\gamma}-\mathrm{Al}_{2} \mathrm{O}_{3}$ to $\alpha-\mathrm{Al}_{2} \mathrm{O}_{3}$, whereas $1: 1 \mathrm{CA} / \mathrm{N}$ molar ratio yielded a monodispersed ultrafine $\mathrm{\alpha}-\mathrm{Al}_{2} \mathrm{O}_{3}[3]$.

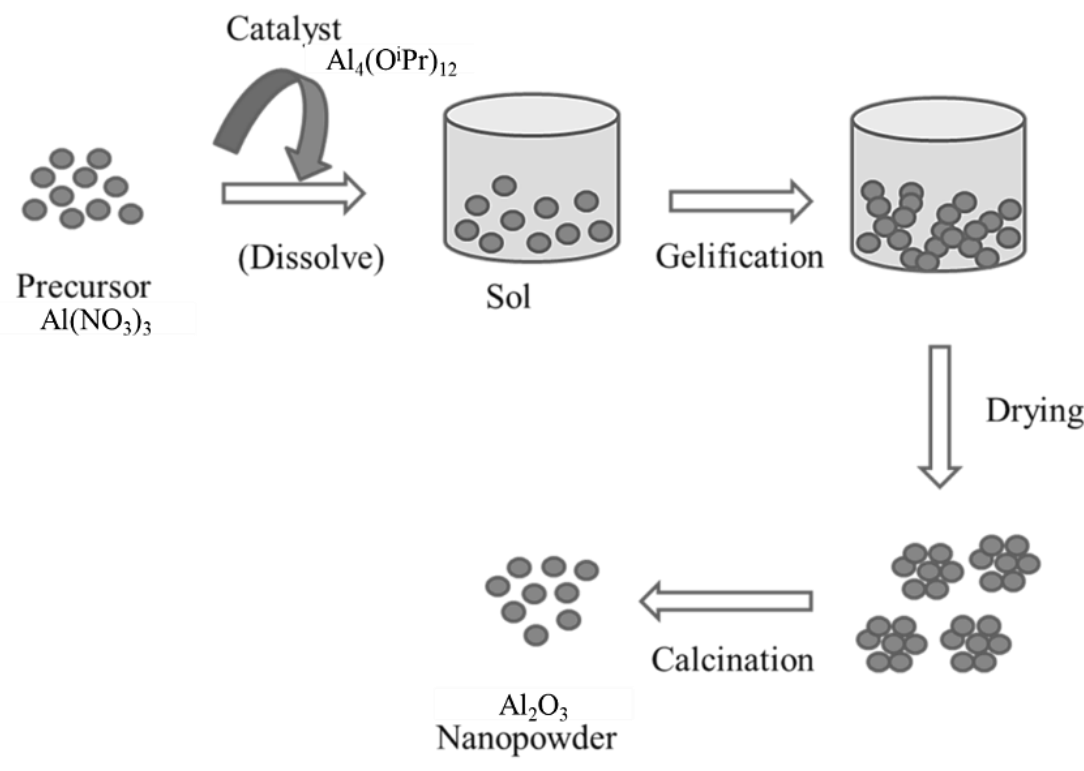

Figure 1 Scheme for the synthesis of alumina nanoparticles by the sol-gel method

Khazaei et al. synthesized porous $y$-aluminium oxide nanoparticles using sodium aluminate liquor as a precursor. The effect of two surfactants namely, polyethylene glycol (PEG) and polyvinyl alcohol (PVA) were investigated for their stabilizing action on alumina nanoparticles (Figure 1). The calcination temperature was maintained at $80^{\circ} \mathrm{C}$. PVA as stabilizing agent offered better structural properties (average crystallite size of $2.063 \mathrm{~nm}$, the average particle size of $46 \mathrm{~nm}$, the specific surface area of $201.1 \mathrm{~m}^{2} / \mathrm{g}$ and pore volume of $0.246 \mathrm{~cm}^{3} / \mathrm{g}$ ) when compared with PEG (average crystallite size of $2.313 \mathrm{~nm}$, the average particle size of 20 $\mathrm{nm}$, the specific surface area (SSA) of $138.8 \mathrm{~m}^{2} / \mathrm{g}$, and pore volume of $\sim 0.166 \mathrm{~cm}^{3} / \mathrm{g}$ ). PEG stabilized synthesis resulted in the formation of ultrafine nanoparticles $(20 \mathrm{~nm})$, whereas PVA stabilized nanoparticles are comparatively larger, thus the adhesion between the nanoparticles was less and remained in a more dispersed state [4]. 
Mirjalili et al. synthesized ultrafine $\alpha$-alumina nanoparticles using aluminium isopropoxide, aluminium nitrate hydrate $(0.5 \mathrm{~mol} / \mathrm{L})$ as precursors and sodium dodecylbenzene sulfonate (SDBS), sodium bis-2-ethylhexyl sulfosuccinate (Na-AOT) as stabilizing agents to prevent the aggregation of nanoparticles. The surfactants played a major role in controlling the size and shape of the nanoparticle and in addition the degree of aggregation has also been influenced by the two stabilizing agents. Using sodium dodecylbenzene sulfonate as a stabilizing agent resulted in the fine and well-dispersed nanoparticles $(20-30 \mathrm{~nm})$. The better stabilization action of SDBS can be attributed to the higher ionization of SDBS in comparison Na-AOT that resulted in negative charge adsorption in the positively charged precursor. This charge-charge interaction decreased particle aggregation [5].

The aim of this work was to use the sol-gel method for the green synthesis of alumina nanoparticles.

\section{METHODS}

\subsection{Plant material and preparation of the extract}

Generally, biosynthesis of nanoparticles occurs when plant aqueous extract undergoes bioreduction process with an aqueous solution of suitable metal salt. Fresh neem (Azadirachta indica) leaves were collected from the institute and washed twice with distilled water to remove all the debris present on it. About $20-30 \mathrm{~g}$ of leaves was crushed with mortar and pestle and the obtained extract was filtered with muslin cloth. The extract was then stored at room temperature for further experiments [6]. The leaves extract contains flavonoids and phenolic acids with various functional groups, which are capable of forming nanoparticles by acting as reducing and stabilizing agents.

\subsection{Biosynthesis of $\mathrm{Al}_{2} \mathrm{O}_{3} \mathrm{NPs}$}

Aluminum chloride (Merck, India) was used as the primary chemical for the synthesis of aluminum oxide nanoparticles. The prepared extract was mixed with saturated solution of aluminum chloride and kept for two hours in magnetic stirrer (REMI, Laboratory Instruments, India) for appropriate mixing of the solutions. The pH change was observed after stirring process to check the reaction occurring between the phytochemicals present in the extract and the metal ions to produce metal oxide nanoparticle. The reaction mixture was then centrifuged at $2500 \mathrm{rpm}$ for 20 minutes using cooling centrifuge (REMI C-24 Plus) to settle down the unused extract and the obtained supernatant was again ultra-centrifuged at 14,000 rpm for 30 minutes. The resulted supernatant was discarded and the pellets were repeatedly washed with water and ethanol and dried in hot air oven at $60{ }^{\circ} \mathrm{C}$ to obtain $\mathrm{Al}_{2} \mathrm{O}_{3} \mathrm{NPs}$. The alumina nanoparticles were characterized by the SEM method.

\section{RESULTS AND DISCUSSION}

Aluminium oxide nanoparticles $\left(\mathrm{Al}_{2} \mathrm{O}_{3} \mathrm{NPs}\right)$ are class of metal oxide nanoparticles that have various biomedical applications due to their excellent physicochemical and structural properties (chemical and mechanical resistence, very good optical characteristics, a porous vast surface area etc.) as well as their low cost of preparation [7]. The synthesis of metal oxide nanoparticles is the major technological challenge. The behavior of aluminium oxide nanoparticles for different applications is determined by the physical, chemical, optical and magnetic properties, which, in turn, are influenced by the structural characteristics of the nanoparticles. Numerous production methods are developed such as sol-gel, precipitation, micro-emulsion, and hydrothermal method. $\mathrm{Al}_{2} \mathrm{O}_{3} \mathrm{NPs}$ have various potential biomedical applications - drug delivery, biosensing, cancer therapy, anti-microbial agens, treatment other diseases such as asthma, biomolecular preservation and stabilisation, and immunotherapy [7]. Due to their biomedical applications, it is needed test their environmental biotoxicity. Table 1 summarizes the data on the synthesis of alumina nanoparticles using various methods and techniques. Thus, it was possible to prepare nanoparticles with sizes from 4 to $100 \mathrm{~nm}$. 
Table 1 Brief description of the different methods applied for the synthesis of the aluminium and aluminium oxide (alumina) nanoparticles used in various research studies

\begin{tabular}{|c|c|c|c|c|}
\hline $\begin{array}{l}\text { Method of } \\
\text { preparation }\end{array}$ & Precursor & Nanoparticle & $\begin{array}{c}\text { Particle size } \\
(\mathrm{nm})\end{array}$ & Reference \\
\hline \multirow[t]{4}{*}{ Sol-gel method } & $\begin{array}{l}\text { aluminium chloride and } \\
\text { aluminium triisopropylate }\end{array}$ & $\mathrm{a}-\mathrm{Al}_{2} \mathrm{O}_{3}$ & - & [2] \\
\hline & aluminium nitrate and citric acid & $\alpha-\mathrm{Al}_{2} \mathrm{O}_{3}$ & $75 \mathrm{~nm}$ & [3] \\
\hline & sodium aluminate liquor & & $20 \mathrm{~nm}$ & [4] \\
\hline & $\begin{array}{l}\text { aluminium isopropyloxide, } \\
\text { aluminium nitrate hydrate }\end{array}$ & $\mathrm{a}-\mathrm{Al}_{2} \mathrm{O}_{3}$ & $20-30 \mathrm{~nm}$ & [5] \\
\hline \multirow{6}{*}{$\begin{array}{l}\text { Precipitation } \\
\text { method }\end{array}$} & SDS, PEG 6000 & $\mathrm{Al}(\mathrm{OH})_{3}$ & $80-100 \mathrm{~nm}$ & [8] \\
\hline & polysulfone and polystyrene & $\mathrm{Al}(\mathrm{OH})_{3}$ & & [9] \\
\hline & $\begin{array}{l}\text { ammonium bicarbonate, } \\
\text { ammonium carbonate, sodium } \\
\text { bicarbonate and sodium } \\
\text { carbonate }\end{array}$ & Y-alumina & $4.7-5.7 \mathrm{~nm}$ & [10] \\
\hline & - & $\mathrm{Y}-\mathrm{Al}_{2} \mathrm{O}_{3}$ & $4.5 \mathrm{~nm}$ & {$[11]$} \\
\hline & polyethylene glycol & $\mathrm{Al}_{2} \mathrm{O}_{3}$ & - & [12] \\
\hline & - & $\begin{array}{l}\gamma \text { and } \alpha \text { phases } \\
\text { of alumina } \\
\text { nanoparticles }\end{array}$ & $20-50 \mathrm{~nm}$ & [13] \\
\hline \multirow{2}{*}{$\begin{array}{l}\text { Micro-emulsion } \\
\text { method }\end{array}$} & Triton $\mathrm{X}-100$ and $\mathrm{n}$-butyl alcohol & - & - & [14] \\
\hline & silane agent & $\mathrm{Al}_{2} \mathrm{O}_{3}$ & - & [15] \\
\hline \multirow[t]{2}{*}{$\begin{array}{l}\text { Hydrothermal } \\
\text { method }\end{array}$} & polyethyleneglycol (PEG) & $\begin{array}{l}\text { Y-aluminium } \\
\text { oxide }\end{array}$ & $10-15 \mathrm{~nm}$ & {$[16]$} \\
\hline & $\begin{array}{l}\text { cationic } \\
\text { (cetyltrimethylammonium } \\
\text { tosylate, CTAT) and anionic } \\
\text { (sodium dodecylbenzene, } \\
\text { sulfonate, SDBS) }\end{array}$ & $\delta-\mathrm{Al}_{2} \mathrm{O}_{3}$ & - & [17] \\
\hline
\end{tabular}

A study has also been conducted to explain the complete process for producing aluminium hydroxide with improved whiteness. In the initial step, the colorant containing aluminium hydroxide was dissolved as the solution. The solution was treated with colorant-collecting reagent and separated as a solid phase. The solid phase was removed from the solution and the aluminium hydroxide was precipitated as a pure white powder.

A

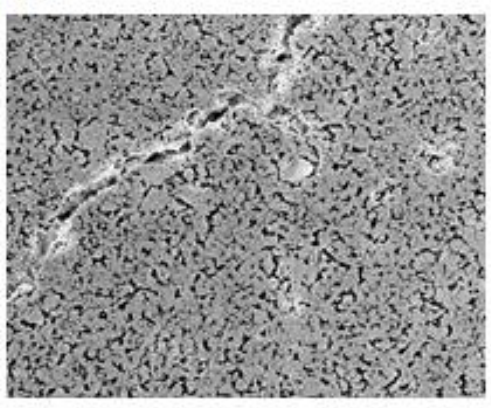

B

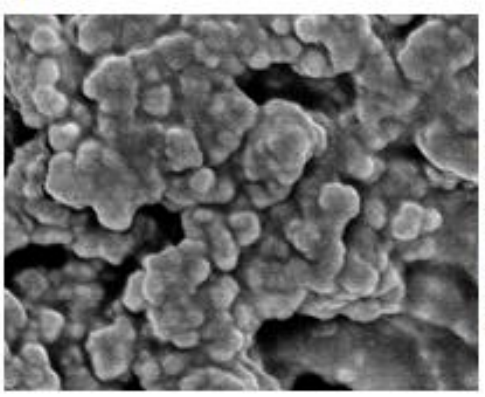

C

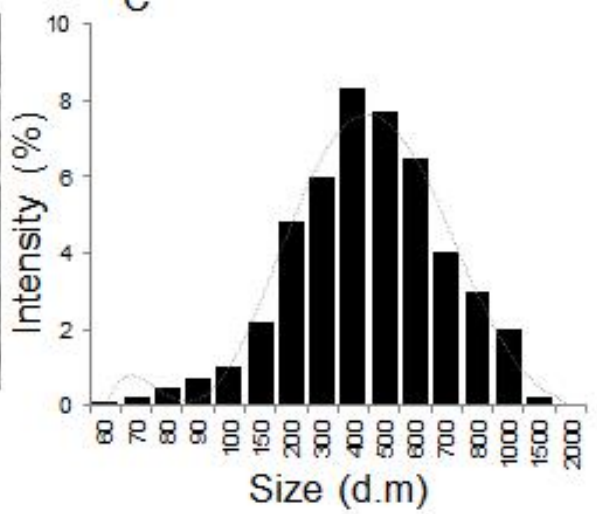

Figure 1 Characterization of alumina nanoparticles - A) SEM images 1000x; B) 30 000x; C) Size distribution 
In this study, alumina nanoparticles were prepared biologically - by green synthesis from neem (Azadirachta indica) leaves. This plant belongs to the so-called ethnomedical herbs, which has antibacterial, antiviral and anticancer properties. Green-synthesized alumina nanoparticles were characterized by the SEM technique. The method showed the irregular arrangement, wherein the spherical shaped nanoparticles were aggregated (Figures 1A,B). Distribution diagram shown in Figure 1C displayed showed a size of nanoparticles from 60 to 1,500 , with a maximum around $200-400 \mathrm{~nm}$. The zeta potential of prepared alumina nanoparticles was $+19.5 \mathrm{mV}$. The size of nanoparticles formed by the sol-gel method ranged from $20-200 \mathrm{~nm}$. From the above results, it is also clear that maintaining the calcination temperature within $800-1,000^{\circ} \mathrm{C}$ results in the formation of ultrafine, monodispersed alumina nanoparticles, which is important for its various applications.

Sutradhar et al. used microwave-assisted green chemistry and synthesized alumina nanoparticles using tea and coffee extracts with a size of 50-200 nm which were spherical in shape, and also oval shaped nanoparticles using triphala extract with an average size of 200-400 nm [18]. Hasanpoor et al. found that average size of clusters of alumina nanoparticles varied with different routes from of $60-300 \mathrm{~nm}$. They used extracts from five different plants (Syzygium aromaticum, Origanum vulgare, Origanum majorana, Theobroma cacao and Cichorium intybus) for their synthesis [19]. Narayanan and Rakesh prepared alumina nanoparticles using lemon extract [20]. Recently, alumina nanoparticles were also synthesized using leaf extract of Ocimum sanctum [21]. Neem extraxt has been used in previous studies for the green synthesis of gold [22], silver [23,24], iron [25], zinc [26,27] and copper [28] nanoparticles. However, to the best of the authors' knowledge, alumina nanoparticles have not yet been synthesized using this plant.

\section{CONCLUSION}

Alumina nanoparticles were prepared by green synthesis from Azadirachta indica, containing a number of phenolic compounds (nimbin, azadirachin, nimbidin, salannin). The nanoparticles slightly aggregated with the most frequent size of $400 \mathrm{~nm}$ and zeta potential $+19.5 \mathrm{mV}$. We expect their further potential in use in biomedical applications, especially those antibacterial and antiviral.

\section{ACKNOWLEDGEMENTS}

This work was supported by the grant FVHE/Pikula/ITA2021. We also thank Operational Programme Research, Development and Education, within the project Center for Tumor Ecology - Research of the Cancer Microenvironment Supporting Cancer Growth and Spread (reg. No.

CZ.02.1.01/0.0/0.0/16_019/0000785). The authors would like to acknowledge the SASTRA Deemed University, Thanjavur-613401, India for infrastructural support in the manuscript.

\section{REFERENCES}

[1] FARAHMANDJOU, M.,GOLABIYAN, N. Synthesis and characterization of Alumina (AI2O3) nanoparticles prepared by simple sol-gel method. Int. J. Bio-Inorg. Hybr. Nanomater. 2016, vol. 5, no. 1, pp. 73-77.

[2] ROGOJAN, R., ANDRONESCU, E., GHITULICA, C., VASILE, B. S. Synthesis and characterization of alumina nano-powder obtained by sol-gel method. UPB Buletin Stiintific, Series B: Chemistry and Materials Science. 2011, vol. 73, no. 2, pp. 67-76.

[3] LI, J., PAN, Y. B., XIANG, C. S., GE, Q. M.,GUO, J. K. Low temperature synthesis of ultrafine alpha-Al2O3 powder by a simple aqueous sol-gel process. Ceramics International. 2006, vol. 32, no. 5, pp. 587-591.

[4] NAZARI, S., KARIMI, G., GHADERI, E., MANSOURI MORADIAN, K.,BAGHERPOR, Z. Synthesis and characterization of $\mathrm{Y}$-alumina porous nanoparticles from sodium aluminate liquor with two different surfactants. International Journal of Nanoscience and Nanotechnology, 2016, vol. 12, no. 4, pp. 207-214.

[5] MIRJALILI, F., MOHAMAD, H.,CHUAH, L. Preparation of nano-scale alpha-Al2O3 powder by the sol-gel method. Ceramics-Silikaty. 2011, vol. 55, no. 4, pp. 378-383. 
[6] AHMED, S., SAIFULLAH, AHMAD, M., SWAMI, B. L.,IKRAM, S. Green synthesis of silver nanoparticles using Azadirachta indica aqueous leaf extract. Journal of radiation research and applied sciences. 2016, vol. 9, no. 1, pp. 1-7.

[7] HASSANPOUR, P., PANAHI, Y., EBRAHIMI-KALAN, A., AKBARZADEH, A., DAVARAN, S., NASIBOVA, A. N., KHALILOV, R.,KAVETSKYY, T. Biomedical applications of aluminium oxide nanoparticles. Micro \& Nano Letters. 2018, vol. 13, no. 9, pp. 1227-1231.

[8] YU, B., TIAN, Z. H., XIONG, J.,XIANG, L. Synthesis of $\mathrm{Al}(\mathrm{OH})(3)$ Nanostructures from $\mathrm{Al}(\mathrm{OH})(3)$ Microagglomerates via Dissolution-Precipitation Route. Journal of Nanomaterials. 2013, vol. 2013.

[9] GOUDARZI, M., GHANBARI, D., SALAVATI-NIASARI, M.,AHMADI, A. Synthesis and Characterization of $\mathrm{Al}(\mathrm{OH})(3), \mathrm{Al} 2 \mathrm{O} 3$ Nanoparticles and Polymeric Nanocomposites. Journal of Cluster Science. 2016, vol. 27, no. 1, pp. 25-38.

[10] PARIDA, K. M., PRADHAN, A. C., DAS, J.,SAHU, N. Synthesis and characterization of nano-sized porous gamma-alumina by control precipitation method. Materials Chemistry and Physics. 2009, vol. 113, no. 1, pp. 244248.

[11] POTDAR, H. S., JUN, K. W., BAE, J. W., KIM, S. M.,LEE, Y. J. Synthesis of nano-sized porous gamma-alumina powder via a precipitation/digestion route. Applied Catalysis a-General. 2007, vol. 321, no. 2, pp. 109-116.

[12] LASHANIZADEGAN, M., FARZI, G.,NIA, N. E. Synthesis and surface modification of aluminum oxide nanoparticles. Journal of Ceramic Processing Research. 2014, vol. 15, no. 5, pp. 316-319.

[13] RAJAEIYAN, A.,BAGHERI-MOHAGHEGHI, M. Comparison of sol-gel and co-precipitation methods on the structural properties and phase transformation of $\mathrm{y}$ and $\alpha-\mathrm{Al} 2 \mathrm{O} 3$ nanoparticles. Advances in Manufacturing. 2013, vol. 1, no. 2, pp. 176-182.

[14] HUANG, K., YIN, L., LIU, S.,LI, C. Preparation and formation mechanism of Al2O3 nanoparticles by reverse microemulsion. Transactions of Nonferrous Metals Society of China. 2007, vol. 17, no. 3, pp. 633-637.

[15] GHEZELBASH, Z., ASHOURI, D., MOUSAVIAN, S., GHANDI, A. H.,RAHNAMA, Y. Surface modified Al2O3 in fluorinated polyimide/Al2O3 nanocomposites: Synthesis and characterization. Bulletin of Materials Science. 2012, vol. 35, no. 6, pp. 925-931.

[16] TABATABAEE, M.,SABERI, N. A Simple Method for Synthesis of $\gamma$-Aluminum Oxide Nanostructure Using PEG as a Neutral Surfactant. Int. J. Bio-Inorg. Hybd. Nanomat. 2012, vol. 1, no. 4, pp. 253-256.

[17] YAACOB, II, BHANDARKAR, S.,BOSE, A. SYNTHESIS OF ALUMINUM HYDROXIDE NANOPARTICLES IN SPONTANEOUSLY GENERATED VESICLES. Journal of Materials Research. 1993, vol. 8, no. 3, pp. 573-577.

[18] SUTRADHAR, P., DEBNATH, N.,SAHA, M. Microwave-assisted rapid synthesis of alumina nanoparticles using tea, coffee and triphala extracts. Advances in Manufacturing. 2013, vol. 1, no. 4, pp. 357-361.

[19] HASANPOOR, M., FAKHR NABAVI, H.,ALIOFKHAZRAEI, M. Microwave-assisted synthesis of alumina nanoparticles using some plants extracts. Journal of Nanostructures. 2017, vol. 7, no. 1, pp. 40-46.

[20] NARAYANAN, M. V.,RAKESH, S. Synthesis of colloidal alumina nanoparticles using green method. IOP Conference Series: Materials Science and Engineering. IOP Publishing, 2018, p. 012150.

[21] SHARMA, P.,SHARMA, N. Antimicrobial activity of alumina nanoparticles synthesized by leaf extract of Ocimum sanctum. International Journal of Engineering Applied Sciences and Technology. 2020, vol. 5, no. 4, pp. 251-253.

[22] ANURADHA, J., ABBASI, T.,ABBASI, S. Green'synthesis of gold nanoparticles with aqueous extracts of neem (Azadirachta indica). Research Journal of Biotechnology. 2010, vol. 5, no. 1, pp. 75-9.

[23] CHAND, K., ABRO, M. I., AFTAB, U., SHAH, A. H., LAKHAN, M. N., CAO, D., MEHDI, G.,MOHAMED, A. M. A. Green synthesis characterization and antimicrobial activity against Staphylococcus aureus of silver nanoparticles using extracts of neem, onion and tomato. RSC advances. 2019, vol. 9, no. 30, pp. 17002-17015.

[24] KHAN, Z., HUSSAIN, J. I.,HASHMI, A. A. Shape-directing role of cetyltrimethylammonium bromide in the green synthesis of Ag-nanoparticles using Neem (Azadirachta indica) leaf extract. Colloids and Surfaces B: Biointerfaces. 2012, vol. 95, pp. 229-234.

[25] PATTANAYAK, M.,NAYAK, P. Green synthesis and characterization of zero valent iron nanoparticles from the leaf extract of Azadirachta indica (Neem). World Journal of Nano Science \& Technology. 2013, vol. 2, no. 1, pp. 06-09. 
[26] NOORJAHAN, C., SHAHINA, S. J., DEEPIKA, T.,RAFIQ, S. Green synthesis and characterization of zinc oxide nanoparticles from neem (Azadirachta indicia). International Journal of Scientific Engineering and Technology Research. 2015, vol. 4, no. 30, pp. 5751-5753.

[27] SOHAIL, M. F., REHMAN, M., HUSSAIN, S. Z., HUMA, Z.-E., SHAHNAZ, G., QURESHI, O. S., KHALID, Q., MIRZA, S., HUSSAIN, I.,WEBSTER, T. J. Green synthesis of zinc oxide nanoparticles by Neem extract as multifacet therapeutic agents. Journal of Drug Delivery Science and Technology. 2020, vol. 59, p. 101911.

[28] ANSILIN, S., NAIR, J. K., ASWATHY, C., RAMA, V., PETER, J.,PERSIS, J. J. Green synthesis and characterisation of copper oxide nanoparticles using Azadirachta indica (Neem) leaf aqueous extract. Journal of Nanoscience and Technology. 2016, pp. 221-223. 